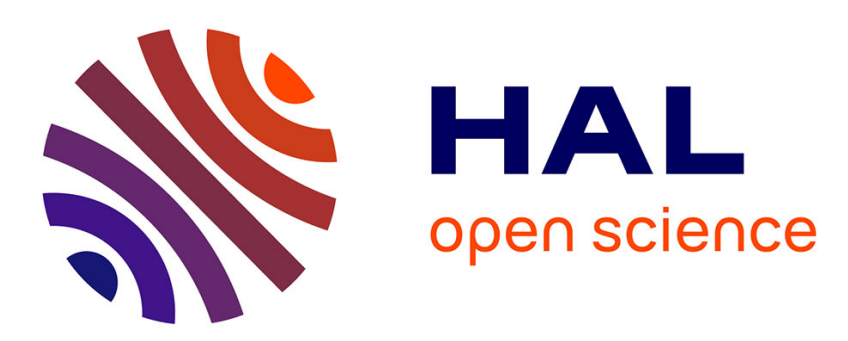

\title{
Using Primary Knowledge: an Efficient Way To Motivate Students and Promote the Learning of Formal Reasoning
}

Florence Lespiau, André Tricot

\section{- To cite this version:}

Florence Lespiau, André Tricot. Using Primary Knowledge: an Efficient Way To Motivate Students and Promote the Learning of Formal Reasoning. Educational Psychology Review, 2019, 10.1007/s10648-019-09482-4 . hal-02112917

\section{HAL Id: hal-02112917 \\ https://hal.science/hal-02112917}

Submitted on 17 Jul 2019

HAL is a multi-disciplinary open access archive for the deposit and dissemination of scientific research documents, whether they are published or not. The documents may come from teaching and research institutions in France or abroad, or from public or private research centers.
L'archive ouverte pluridisciplinaire HAL, est destinée au dépôt et à la diffusion de documents scientifiques de niveau recherche, publiés ou non, émanant des établissements d'enseignement et de recherche français ou étrangers, des laboratoires publics ou privés. 


\section{Using Primary Knowledge:}

an Efficient Way To Motivate Students and Promote the Learning of Formal Reasoning

Florence Lespiau and André Tricot

CLLE-LTC - Cognition, Langues, Langage, Ergonomie

CNRS and University of Toulouse

Toulouse, France

NOTICE: this is the author's version of a work that was accepted for publication in Educational Psychology Review. Changes resulting from the publishing process, such as peer review, editing, corrections, structural formatting, and other quality control mechanisms may not be reflected in this document. Changes may have been made to this work since it was submitted for publication. A definitive version was subsequently published in Educational Psychology Review, [Lespiau, F. \& Tricot, A. (2019). Using primary knowledge: an efficient way to motivate students and promote the learning of formal reasoning. Educational Psychology Review, https://doi.org/10.1007/s10648-01909482-4].

Correspondance: Florence Lespiau florence.lespiau@gmail.com 


\begin{abstract}
According to Geary's evolutionary approach, humans are able to easily acquire primary knowledge and, with more efforts, secondary knowledge. The present study investigates how primary knowledge contents can facilitate the learning of formal logical rules i.e. secondary knowledge. Framing formal logical problems in evolutionary salient contexts should increase learners' efficiency, motivation and engagement in learning compared with framing logical problems in secondary knowledge. In two experiments, high school students $(n=210)$ had to train with syllogisms of unknown content (to reduce the use of prior knowledge) and which could be related to primary knowledge (rules about invented food and animals) or secondary knowledge (fictitious mathematics and grammar rules) in order to best pass a final test. The training phase was compulsory or left to learners' choice. In a third experiment, participants (university students, $n=227$ ) were confronted with three phases: (i) a priming phase consisting of problems with primary or secondary knowledge contents, then (ii) a training phase consisting of secondary knowledge only and (iii) the final test. Results confirmed the positive influence of primary knowledge in a learning task: participants were more efficient, more motivated, more confident and experienced less cognitive load when confronted with primary knowledge compared to secondary knowledge. In particular, primary knowledge favored the involvement and persistence of learners in the training phase regardless of their personal characteristics unlike secondary knowledge. Finally, presenting primary knowledge first and then secondary knowledge was more efficient both in terms of performance and motivation. The evolutionary approach to knowledge would provide a framework for developing a way to present new content that is cost-efficient in keeping learners motivated, whatever their age or personal characteristics.
\end{abstract}

Keywords: primary/secondary knowledge, evolutionary approach, engagement, learning. 


\section{Introduction}

Over the course of our lives, we constantly change our knowledge based on our experience. Learning is the way to adapt to our daily environment. We learn everywhere and the dedicated place of learning is school. School enables students to learn knowledge that is difficult to acquire by themselves or through simple social interactions (e.g., grammar rules, mathematics). Yet individuals acquire knowledge outside school without special instruction (e.g., mother tongue, food identification). The evolutionary approach (Geary \& Berch, 2016) differentiates two types of knowledge: secondary knowledge (i.e., knowledge that appeared recently during the evolution of the species) for which individuals must invest effort and time, and primary knowledge (i.e., knowledge that appeared early in the evolution of species) that would be easily and rapidly acquired. Secondary knowledge requires

considerable investment and its processing rarely motivates learners, whereas primary knowledge seems to be intrinsically motivating. This distinction between primary and secondary knowledge may be similar to Nairne's work on adaptive memory, suggesting that our memory systems evolved to better remember information that is related to our survival (Nairne, 2016; Nairne, Pandeirada \& Thompson, 2008). For example, individuals retain information related to animated objects (e.g. predators) better than unanimated objects (e.g. furniture) (Gelin, Bonin, Méot \& Bugaiska, 2018; Leding, 2018). This study aimed to extend the evolutionary approach to more complex learning tasks and investigate whether an evolution-related context can also foster engagement in learning.

\subsection{The knowledge we have to learn in schools}

Human beings are curious by nature and are particularly gifted when it comes to learning (Sweller, 2015). Nevertheless, it is not uncommon for a student to see their enthusiasm drop drastically when they have to study (Geary \& Berch, 2015). One explanation would be related to the nature of the knowledge learned in school: it seems far removed from our daily concerns, so that it is rarely found to be of direct use. Indeed, it seems difficult to maintain our motivation to learn Pythagoras' theorem if we do not understand how to apply it in a useful way (Roszkowski \& Soven, 2010). Schools were created to facilitate children's learning the secondary knowledge that is very difficult to learn alone or through simple social interactions (e.g. imitation, observation) but which is necessary to be a successful adult in society (Geary \& Berch, 2016). One goal of learning is to acquire skills that make it possible to reason about a new problem by identifying relevant information about the structure of this problem. Subsequently one is able to transfer this knowledge to new problems as long as these problems have the same structure, i.e. as long as the conditions for using this knowledge are met (as with formal logic 
rules) (Binkley et al., 2012; Kaminski, Sloutcky \& Heckler, 2006; Hummel \& Holyoak, 2005; Tricot, 2018). This kind of learning requires effort, time and significant motivation.

A major educational challenge for our societies is to keep learners motivated beyond their natural curiosity to involve them in a long-term learning process. Motivation is indeed an important key to learning and predicts individual performance, satisfaction and well-being (Ellis, 2008; Kim, Park \& Cozart, 2014; Ryan \& Deci, 2000). The principal concern of teachers and parents is therefore to promote motivation, the enjoyment of learning and the commitment to learning tasks (Braver et al., 2014). However, extrinsic motivation, such as parental support or societal expectations, is often necessary to maintain learners' engagement. Not all individuals are equal in their motivation to learn. The motivational profile can be described through achievement goals (among other indicators) that reflect the reasons why a learner performs an academic task. Four types of goals can be considered: mastery approach (focused on task performance and personal competence), mastery avoidance (focused on avoiding personal incompetence), performance approach (focused on achieving normative competence) and performance avoidance (focused on avoiding normative incompetence) (Elliot \& McGregor, 2001; Elliot \& Murayama, 2008). A learner's type of achievement goal predicts their learning trajectory (Huff, Stripling, Boyer \& Stephens, 2016) and thus enables the development of appropriate instructions and feedback. Feedback is another crucial element in learning situations as it supports and motivates learners (Hattie \& Timperley, 2007). It reduces cognitive load and allows the student to focus attentional resources on aspects of the problem-solving approach that need to be modified. This is critical due to the limited capacity of the working memory system (Paas, Renkl \& Sweller, 2003). Indeed, the capacity of working memory is limited in quantity and time (Paas \& Ayres, 2014) and mental effort must not exceed this capacity to allow learning. The idea is then to reduce the cognitive load not necessary for learning (such as that related to presentation modalities) in order to allocate cognitive resources to useful cognitive load (learning activity and processing of the interactivity of the elements to be learned) (Sweller, Ayres \& Kalyuga, 2011).

Learning is therefore a particularly difficult and complex process. Learners work so hard to learn secondary knowledge because it is culturally important and necessary for life in today's societies that are far removed from the considerations that were faced by our ancestors (Richerson \& Boyd, 2005). However, not all knowledge is difficult nor time-consuming to learn. For example, we all manage to understand and speak our mother tongue relatively quickly and almost without being aware of it, whereas learning the explicit grammar rules of this language is much more difficult and time- 
consuming. This is even more the case for learning a second language. However, being able to speak our mother tongue is not simple (e.g. it implies differentiating phonemes, synchronizing phonatory muscles, etc.) but its acquisition is aided by inherent neural, perceptual, and cognitive biases that provide the basic structure for children's comprehension and production of language. Biologicallysecondary domains have this built-in structure to aid children's learning in these areas. According to the evolutionary approach to knowledge (Geary \& Berch, 2016), knowledge can be divided into two types according to its acquisition time and adaptive utility.

\subsection{Primary and secondary knowledge}

According to a recent theory in evolutionary psychology (Geary, 2007, 2008; Geary \& Berch, 2015, 2016), our brain evolved to efficiently process (through attentional and cognitive mechanisms) certain adaptive types of information called primary knowledge as illustrated with fitness-relevant words and memory (Nairne, 2016). Thus, we are pre-wired to easily and quickly acquire knowledge related to folk psychology (e.g. self-awareness, face recognition, facial expressions, language, group dynamics, theory of mind), folk biology (e.g. fauna, flora, food) and folk physics (e.g. navigation). Moreover, in addition to the evolved biases that allow rapid acquisition without recourse to cognitive resources, we may be particularly motivated to deal with this type of knowledge because it is directly relevant to individual adaptation and survival (Geary, 2008; Geary \& Berch, 2016; Geary \& Bjorklund, 2000). We manage to master our mother tongue quickly and without special effort because it has an inherent structure that guides learning that in turn evolved thanks to the adaptive advantages of social communication. The acquisition of a mother tongue is universal but nuanced according to the environment.

We also have a tremendous ability to create new knowledge. This accumulation of new so-called secondary knowledge has occurred too quickly with regard to evolutionary time: the attentional and cognitive biases that facilitate the acquisition of primary knowledge have not evolved fast enough to favor the learning of secondary knowledge (Richerson \& Boyd, 2005; Youssef, Ayres \& Sweller, 2012). Hence, such secondary knowledge is difficult and takes a long time to acquire, very demanding in cognitive resources, and often necessitating extrinsic motivation (Geary \& Berch, 2016). It should also be noted that the more recent the content is from an evolutionary perspective, the more difficult it will be to learn (Geary, 2007). Schools are therefore used to fill the gap between the primary knowledge that individuals acquire effortlessly and the "academic" knowledge that is difficult to learn (Geary \& Berch, 2016). 
Primary and secondary knowledge can be thought of as incompatible due to their opposite characteristics in terms of speed, cognitive costs and motivation to be processed. However, secondary knowledge is built from primary knowledge. People born in the southwest of France acquire "a" French mother tongue depending on their environment (regional dialect). They use this knowledge to learn the grammatical rules of "the" French language and perhaps another language (Roussel, Joulia, Tricot \& Sweller, 2017; Sweller, Ayres \& Kalyuga, 2011). Similarly, we construct symbolic cardinal values (e.g. counting by numbers) from an approximate number system (e.g. innate ability to compare quantities approximately) (Chu, vanMarle \& Geary, 2015). Already acquired primary knowledge is often neglected in education precisely because it is no longer to be learned, but it could be an asset in promoting the acquisition of some forms of secondary knowledge. Novice learners can thus learn to use primary strategies (e.g. general problem-solving strategies) to solve a variety of secondary problems, promoting learning and transfer when instructions encourage the use of these already acquired strategies (Youssef et al., 2012; Youssef-Shalala, Ayres, Schubert \& Sweller, 2014). The idea of trying to develop activities that use learners' primary knowledge is therefore promising.

Indeed, numerous studies demonstrated that primary knowledge facilitates the acquisition of secondary knowledge, particularly through the use of primary mechanisms that increase working memory capacity and reduce the impact of cognitive load, thereby promoting learning. For example, studies show that working memory can be virtually increased and cognitive load shared when working collaboratively on complex tasks that would be a natural learning situation (Kirschner, Paas \& Kirschner, 2011; Kirschner, Paas, Kirschner \& Janssen, 2011; Nokes-Malach, Richey \& Gadgil, 2015; Paas \& Sweller, 2012). Other research has focused on how human movement facilitates learning. Indeed, we naturally learn through observation and imitation (Van Gog, Paas, Marcus, Ayres \& Sweller, 2009). Thus, a dynamic representation of a procedure to be learned is more effective than a static one (Castro-Alonso, Ayres \& Paas, 2015). Similarly, results on embodied cognition have shown that the involvement of the most basic motor system, such as gesture, decreases cognitive load (Paas \& Sweller, 2012; Ping \& Goldin-Meadow, 2010) and that movement facilitates learning (Glenberg, Goldberg \& Zhu, 2011; Mavilidi, Okely, Chandler, Cliff \& Paas, 2015; Toumpaniari, Loyens, Mavilidi $\&$ Paas, 2015).

Little research has been conducted linking the primary and secondary knowledge suggested by Geary and Berch's (2016) evolutionary approach in a direct manner, i.e. by comparing performance on the same task that varied only according to the knowledge type involved (primary vs. secondary 
knowledge). One exception was led by Lespiau and Tricot (2018) who investigated whether the hypothetical characteristics of primary knowledge (i.e., low cost in cognitive resources and intrinsically motivating) could facilitate the resolution of logical problems, with logical problems being considered as secondary knowledge. The main hypothesis was, as part of logical problem solving, using primary knowledge contents (even with unknown, unfamiliar words) would also improve individual performance and motivation while reducing perceived cognitive load whereas using secondary knowledge contents would undermine individuals' motivation and performance. There is therefore reason to believe that using primary knowledge content could facilitate the processing and learning of secondary knowledge. In two experiments, Lespiau and Tricot (2018) compared primary and secondary knowledge used as contexts for logical reasoning tasks. They showed that primary knowledge context increases performance, emotional and cognitive investment, and decreases perceived cognitive load. However, the results also showed that when presented before secondary knowledge, primary knowledge has a positive impact on logical responses. The authors therefore concluded that, in an educational environment, primary knowledge as a context could be a good way to introduce a new topic.

This primary knowledge effect can be explained by the fact that the human cognitive architecture and the knowledge acquisition process may have evolved in a similar way to biological structures (Sweller, 2016; Sweller \& Sweller, 2006). As a result, our working memory has a limited capacity which forces us to select relevant information rather than evaluate all information indiscriminately. Processing new information and knowledge requires working memory resources. This need for cognitive resources does not apply to primary knowledge despite its complexity (e.g. speaking is a complex activity combining motor skills, sounds, gesture, etc.) since our cognitive system has evolved to deal with it efficiently (Sweller, 2008). Thus, due to its characteristics, primary knowledge could have a positive effect in learning since it would reduce unnecessary cognitive load and have a motivating effect.

The evolutionary approach differentiates two types of knowledge according to their acquisition time and their adaptive utility. We are predisposed to acquire primary knowledge that becomes intrinsically motivating, easily and quickly processed without cognitive resources, while we struggle to learn secondary knowledge that is not motivating and we need to invest effort, time and cognitive resources to do so. Primary mechanisms could also be used to make it easier to learn secondary 
knowledge and to continue learning even when the difference between the two types of knowledge is extremely large.

\section{Present study}

This paper is in line with research involving the evolutionary approach in learning (Paas \& Sweller, 2012) or in memory (Nairne, 2016) and advances Lespiau and Tricot (2018), seeking to use the evolutionary approach to knowledge to promote learners' motivation and performance in a real learning task rather than its application to an artificial task. To this end, we conducted three experiments in which the main task was to learn the rules of formal logic. The formal knowledge valued by society as abstraction skills (Binkley et al., 2012; Cosmides \& Tooby, 2004; Markovits \& Lortie-Forgues, 2011) consists of secondary knowledge since it requires time and effort to be learned. We have indeed not evolved to reason logically but to be efficient most of the time and our "daily" reasoning is far from conforming to logical norms (Stanovich \& West, 2000). In addition, logical problems have the methodological advantage of being easily adaptable to various contents. We used the logical reasoning framework as secondary knowledge by varying contents to assess the effects of primary knowledge. In the first two experiments, participants had to practice solving logical problems whose content was linked to primary knowledge (food, animal characteristics) or secondary knowledge (grammatical rules, mathematics) in order to pass a final test as successfully as possible. The training phase was compulsory or left to the learners' choice. In a third experiment, participants were confronted with three phases: (i) a priming phase consisting of problems with primary or secondary knowledge contents, then (ii) a training phase consisting of secondary knowledge and (iii) the final test. We measured not only performance, but also emotional and cognitive investment, confidence in given responses and perceived cognitive load.

The first objective was to test the characteristics of primary and secondary knowledge defined by the evolutionary approach. Thus, problems with primary knowledge contents would lead to higher performance, higher motivation, higher confidence and lower perceived cognitive load compared to problems with secondary knowledge contents (Hypothesis 1).

The second objective was to explore how primary knowledge could be useful for learning (Hypothesis 2). As a result of their speed and ease of processing, primary knowledge would release cognitive resources for learning logic rules (secondary knowledge) compared to secondary knowledge contents that would consume more cognitive resources. Consequently, final test performance would be 
higher when participants were confronted with primary knowledge contents. Moreover, since primary knowledge is intrinsically motivating, exposure to such information would help motivate individuals and increase the number of exercises performed during the training phase.

Finally, we wanted to investigate whether the characteristics of primary knowledge and its potential beneficial effects on learning applied to all individuals, regardless of their characteristics (Hypothesis 3).

\section{Experiment 1}

This first experiment aimed to evaluate the performance, investment and transfer capacities of individuals when the training phase is compulsory.

\subsection{Method}

\subsubsection{Participants}

The participants were 105 high school students in France (52 boys, 53 girls, mean age was 15.00 \pm 0.46 ). They were asked to self-assess, on analogic visual scales, their level in mathematics (from 0 to 100,0 meaning that they considered themselves as poor in mathematics, and 100 meaning that they considered themselves as good in mathematics) and their interest in playing logic games (from 0 to 100,0 meaning that they did not like playing logic games at all, and 100 meaning that they very much liked playing logic games). They estimated their level in mathematics at 55.28/100 ( \pm 29.32$)$, their interest in logic games was 61.35/100 ( \pm 23.04$)$ and $83 \%(n=87)$ never played (or very little) logic games.

\subsubsection{Materials}

The experiment consisted of two phases: a training phase and a test phase. In the training phase, each participant read the following instructions:

We will now propose statements. These statements will be as follows:

"All things that have an engine need oil,

Cars have an engine,

So cars need oil."

The premises (first two lines) must be considered as true. 
The conclusion (last line) should only be accepted if it follows logically from the premises.

For each statement, you will have to judge whether or not the different conclusions proposed follow logically from their premises.

You will have to fill in several worksheets. Answer the statements in the order they are presented (once the sheet is turned, do not go back). If you wish, you can use the blank parts of each sheet as a draft, but only the checked answers will be counted.

The purpose of these exercises is to have you complete a "final test". Take the time you need to practice and try to get as many correct answers as possible in the final test!

Twenty-four syllogisms for each type of knowledge were created following the previous work method that used conditional reasoning (Lespiau \& Tricot, 2018). They were composed of a universal affirmative first premise as well as a particular affirmative second premise and conclusion, or of a universal affirmative first premise as well as a particular negative second premise and conclusion. The contents aimed to reduce previous knowledge as much as possible using words that did not exist. Here are some examples of syllogisms used in the experiment:

Primary knowledge contents (food and animal characteristics):

All ronvacs are wild and herbivorous,

Yellow horned cachuls are ronvacs,

So yellow horned cachuls are wild and herbivorous (valid).

All loutas are sweet and juicy,

The white rouli is not a louta,

So the white rouli is not sweet and juicy (invalid).

Secondary knowledge contents (grammar and mathematics):

All Foster equations are of the type $x=\sqrt{ }(3 b-2 a c)$,

The Jyrog formula is a Foster equation,

So the Jyrog formula is of the type $x=\sqrt{ }(3 b-2 a c)$ (valid).

All sendamin common names end with -li in the plural,

"Alda" is not a sendamin common name,

So "alda" does not end with -li in the plural (invalid). 
Participants responded to each syllogism by checking the box "the conclusion follows logically from the premises" or the box "the conclusion does not follow logically from the premises".

The test phase consisted of four syllogisms using the neutral terms "ABC" and the forms of syllogisms seen in the training phase (" $A$ is $B, C$ is $B$, So $C$ is $A$ " invalid, " $A$ is $B, C$ is $A$, So $C$ is $B$ " valid, " $A$ is $B, C$ is not $B$, So $C$ is not $A$ " valid, " $A$ is $B, C$ is not $A$, So $C$ is not $B$ " invalid).

\subsubsection{Procedure}

Participants were invited for one hour of mandatory study to participate in this paper and pencil experiment. They were given an eighteen-page booklet. It contained a first experimental part (40 minutes long including the training phase and the test) and a second part of logic games to enable them to fill the time until the end of the hour and to allow each participant to respond at their own pace. On this booklet, there were six pages of syllogisms (four syllogisms per page) for the training phase. Each participant was confronted with primary knowledge contents only or secondary knowledge contents only. This training was mandatory, i.e. participants had answer the 24 syllogisms before they could attempt the final test. The session leader insisted orally on the importance of taking the training seriously to pass the final test as successfully as possible.

In addition to their (i) performance during the training phase and (ii) in the final test (in percentages), for each page of syllogisms, participants had to provide information on an analogic visual scale (from 0 to 100): How much they (iii) "enjoyed thinking about the questions" (emotional investment); How much they (iv) "wanted to find the correct answers" (cognitive investment/motivation); How much they were (v) "confident about their given answers" (confidence); and - How much they agreed with two sentences (vi) "the subject was complex", "you concentrated a lot to do the task" and "the experiment was very easy for you" (perceived cognitive load).

At the end of the experiment, participants responded to some personal information including their estimated level in mathematics (as mathematical abilities have been associated with logical skills, Lespiau \& Tricot, 2018; Morsanyi, Devine, Nobes \& Szücs, 2013) and their enthusiasm for solving logical problems. They were also required to complete a questionnaire about their achievement goals (mastery approach, mastery avoidance, performance approach and performance avoidance) (Elliot \& McGregor, 2001 adapted for French by Darnon \& Butera, 2005): this questionnaire is composed of statements about the participant's attitude in class (e.g. "I want to learn as much as possible from the class", "I just want to avoid doing poorly") corresponding to the different achievement goals (3 items 
for each achievement goal); participants must answer on a Likert scale regarding the truth of this statement ( 1 "not at all true of me" to 7 "very true of me"), allowing us to obtain a score for each achievement goal.

\subsubsection{Data analyses}

We expect primary knowledge to increase performance in the training phase (Hypothesis 1) and in the final test (Hypothesis 2). Having benefitted from primary knowledge training, participants should be more motivated, more confident in their responses and should experience lower cognitive load. Due to the nature of the two knowledge types, personal characteristics should have a greater impact on participants' behavior when faced with secondary knowledge contents than when faced with primary knowledge contents (Hypothesis 3): for example, one would expect participants to perform better or have more confidence in their responses if they feel they have a high level in mathematics only faced with secondary knowledge content (since we would be efficient with primary knowledge regardless of our characteristics).

Repeated t-tests were used to examine the differences in performance between the themes of the two knowledge types (i.e. animal characteristics and food for primary knowledge; grammar and mathematics for secondary knowledge). ANCOVAs were used to highlight the influence of the knowledge types by taking into account the estimated level in mathematics, gender, age of participants as well as their different achievement goal scores (Pearson correlations were also used to investigate the relation between those covariables and observed variables). ANOVAs and Tukey post-hoc tests investigated the interactions between knowledge types and exercise pages. Means were noted $\mathrm{M}$ and standard deviation $( \pm)$. All variables were scaled for analyses and performed with the free software $\mathrm{R}$ 3.3.2.

\subsection{Results}

\subsubsection{Preliminary analyses}

There was no difference in performance for the primary domains of food $(M=77.20 \pm 16.92)$ nor animals $(\mathrm{M}=78.30 \pm 18.44)(p=.48)$. There was no difference in performance for the secondary domains of grammar $(M=62.66 \pm 19.77)$ nor mathematics $(M=59.61 \pm 15.95)(p=.16)$. 


\subsubsection{The two knowledge types}

Compared with secondary knowledge training, primary knowledge content promoted performance throughout the training phase, enjoyment of answering questions, as well as the wish to find the correct answers and the confidence in the given answers. It also reduced the perceived cognitive load. However, the knowledge type used in the training phase had no influence on the final test performance (for all statistics, see Table 1).

Whatever the knowledge type, the performances for a given type of knowledge did not differ according to the exercise pages ( $p s>$.73). Compared to problems with secondary knowledge content, problems with primary knowledge content increased performance almost systematically during the training phase. However, final test performance did not differ from a chance score and did not appear to be affected by the type of knowledge used during training (Figure 1).

Among participants, 38\% $(\mathrm{n}=40)$ felt they had learned something during the experiment; participants who had been confronted with primary knowledge contents tended to have this impression more $(47 \%, \mathrm{n}=25)$ than those who had been confronted with secondary knowledge contents $(29 \%$, $\mathrm{n}=15)\left(\chi^{2}(1)=3.00 ; p=.08\right)$.

\subsubsection{Personal characteristics}

The influence of personal characteristics on the measured variables did not vary according to the knowledge type involved in the training phase. The higher the estimated level in mathematics, the higher was the confidence in the given responses $\left(r=0.26, p<.001 ; F(1,96)=5.86, p=.02, \eta^{2} p=0.06\right)$. The higher the mastery approach goal score, the more participants wanted to find the correct answers $\left(r=0.15, p<.001 ; F(1,96)=6.32, p=.01, \eta^{2} p=0.06\right)$. The other achievement goals or the gender of the participants did not have significant impact on the measured variables.

\subsubsection{Discussion}

In line with previous works (Lespiau \& Tricot, 2018), primary knowledge content promoted performance, emotional and cognitive engagement, confidence in responses and decreased perceived cognitive load in a concrete learning task (Hypothesis 1). While participants were better when they had to process primary knowledge content, even unknown and unfamiliar knowledge, their performance was not higher in the final test (compared to secondary knowledge training). Imposing training with primary or secondary knowledge contents would therefore not seem to favor transfer skills (Hypothesis 
2). This mandatory training may also have decreased the expression of personal characteristics in this experiment. However, in an ecological learning situation, learners are more autonomous and choose whether they wish to keep practicing. This involvement in the exercises proposed by the teachers is essential. The following experiment gave participants the choice of whether or not to continue practicing.

\section{Experiment 2}

Experiment 2 aimed to investigate the positive impact of primary knowledge on the importance and duration of engagement in a learning task, particularly on the choice to continue practicing before attempting the final test. It would also enable more efficient exploration into the effect of individual differences on the choice to pursue training based on the knowledge type involved.

\subsection{Method}

\subsubsection{Participants}

The participants were 105 high school students in France (66 boys, 39 girls, mean age was $14.99 \pm 0.51)$. They estimated their level in mathematics at $60.26 / 100( \pm 26.35)$, their interest in logic games was 66.90/100 ( \pm 25.95$)$ and $87 \%(n=91)$ never played (or very little) logic games.

\subsubsection{Materials, procedure and data analyses.}

Material, procedure and data analyses were similar to those of Experiment 1. The only difference is that at the end of each page of the training phase, participants chose to continue practicing or to proceed directly to the final test.

Both the performance and the choice to extend training would be more important when participants were faced with primary rather than secondary knowledge contents (Hypothesis 2). Individual differences would influence participants' performance or decisions to continue, especially when faced with secondary knowledge (Hypothesis 3).

The same analyses as in Experiment 1 were conducted, as well as mediation and survival analyses. Dependent variables, as well as other demographic variables such as estimated level in mathematics, logic, liking logic games and different achievement goal scores were recoded as low vs. high levels from the median of observations for the two types of knowledge separately. The aim was to explore 
whether continuing to the end of the training phase could be explained by personal characteristics (survival analyses (Allison, 2014) to determine whether the characteristics of our experiment or of the participants promote "survival", the persistence of participants in the training phase).

\subsection{Results}

\subsubsection{The two knowledge types}

Presenting training with primary knowledge content increased the number of exercise pages completed (persistence in the training phase), the total relative performance in the training phase and marginally raised the performance in the final test (Table 2).

When each knowledge type is taken separately, the performances did not differ according to the exercise pages ( $p s>.66)$. However, unlike in Experiment 1, when the choice was left to the participants to continue the practice or not, the performances no longer differed between the knowledge types, and this occurred quite quickly (from the second exercise page and, more importantly, from the third, Figure 2). The analyses differentiating between the $25 \%$ of participants who performed better on the first two pages and the other participants did not reflect a specific pattern regarding the evolution of the two knowledge types.

The knowledge type was always a better predictor of the observed variables ( $p s<.03$ ) except for the perceived cognitive load $(p=.97)$. The number of exercise pages completed did not modulate or mediate any observed variable except the perceived cognitive load, which increased with the number of pages completed (knowledge type: $\mathrm{b}=0.003, \mathrm{SE}=0.07, p=.97$; exercise pages: $\mathrm{b}=0.21, \mathrm{SE}=0.02$, $\left.p<.001 ; \mathrm{R}^{2}=0.13\right)$.

\subsubsection{Personal characteristics}

The number of exercise pages completed was positively influenced by mastery goals only, meaning that participants with a score related to mastery goals (avoidance and approach) persisted more in the training phase (avoidance, $r=0.29, p<.001 ; F(1,96)=8.06, p=.005, \eta^{2} p=0.08$; and approach, $r=0.23$, $\left.p<.001 ; F(1,96)=4.38, p=.04, \eta^{2} p=0.04\right)$. In addition, the higher the estimated level in mathematics, the higher was the relative performance during the training phase $(r=0.17, p<.001 ; F(1,96)=4.66, p=.03$, $\left.\eta^{2}{ }_{p}=0.05\right)$. 
Regarding the characteristics that influence participants' greater persistence in the task, survival analyses essentially showed an influence of the knowledge type used: primary knowledge promoted participants' commitment until the end of the training $\left(\chi^{2}(1)=4.5, p=.03\right)$. Women $(\mathrm{M}=3.92 \pm 1.53)$ persevered longer than men, completing more pages $(M=2.88 \pm 1.68)\left(\chi^{2}(1)=9.5, p=.002\right)$. Regarding primary knowledge, there was no particular survival context: no characteristics increased the persistence of participants in the task. However, regarding secondary knowledge, survival/persistence during the training phase was promoted by a higher wish to find the correct answers $\left(\chi^{2}(1)=3.9, p=.04\right)$ (high wish $\mathrm{M}=4.38 \pm 7.72$ vs. low wish $\mathrm{M}=3.52 \pm 1.67$ ) and by a higher score of mastery avoidance $\left(\chi^{2}(1)=8.3, p=.004\right)$ (high score $M=4.60 \pm 1.75$ vs. low score $\left.M=3.36 \pm 1.52\right)$ (Figures 3).

\subsubsection{Discussion}

Experiment 1 showed that problems with primary knowledge content compared to those with secondary knowledge content almost systematically lead to higher performance throughout the training phase (Hypothesis 1). However, when participants could choose whether or not to continue the exercises as in Experiment 2 (i.e. when they were given enough autonomy that could act as a motivation), those who persisted in the training phase no longer showed any difference in performance between problems with primary or secondary knowledge contents. The graphical trend even illustrates an increase in the performance of secondary knowledge to match primary knowledge performance (Figure 2).

Experiment 2 reinforced the positive influence of primary knowledge in a learning task: primary knowledge content encouraged the involvement and persistence of learners in the training phase, whatever their personal characteristics (Hypothesis 3). Indeed, regarding persistence in the training phase for primary knowledge, no personal characteristics seemed to intervene (intrinsically motivating characteristic of primary knowledge) while the persistence faced with secondary knowledge was favored by the wish to find the correct answers and a high avoidance mastery score. Participants who were more likely to be afraid of missing an element for the final test (high avoidance mastery score) would continue training until the end. Unlike primary knowledge, commitment in solving tasks involving secondary knowledge (because they require cognitive resources and are not intrinsically motivating) would require particular motivation and personal characteristics. Investment in the task is therefore a real necessity to foster the learning process of secondary knowledge. One way to promote the enjoyment and commitment of individuals in a task would be to present content related to primary knowledge first (Lespiau \& Tricot, 2018). 
Moreover, these two experiments seem to show that participants were efficient in dealing with primary knowledge but that this would not be enough to learn. The results did not provide any clear indication of an increased transfer capacity, either after primary or secondary content training (Hypothesis 2). One explanation could be that (i) individuals are efficient most of the time on primary knowledge content (even unknown) and that this kind of content alone does not allow extraction of the rule and that (ii) secondary knowledge saturates working memory and prevents learning the rule (e.g. participants should be more motivated or given more time to practice learning the rules). Moreover, the tasks used in these experiments were far from ecological. In particular, in all learning situations, individuals benefit from feedback on their response. As shown previously by Kirschner, Sweller and Clark (2006), it is not enough to confine oneself to primary knowledge to learn. Rather, primary knowledge could be a means of motivating individuals by bringing them all to the same level and reassuring them about their skills. Thus, the third experiment aimed to explore the influence of the "primary knowledge - secondary knowledge" sequence (reformulation of Hypothesis 2) on participants' performance while including efficient and informative feedback (Hattie \& Timperley, 2007).

\section{Experiment 3}

Experiment 3 aimed to investigate, in a more ecological manner, the positive influence of primary knowledge on learning when presented first, before the secondary knowledge content to be learned.

\subsubsection{Participants}

The participants were 227 university students in France (46 men, 181 women, mean age was 22.03 \pm 6.03 ), approached by University Facebook groups. Participants estimated their level in mathematics at 48.30/100 ( \pm 28.08$)$, their interest in logic games was 71.84/100 $( \pm 28.65)$ and $73 \%$ $(n=166)$ never played (or very little) logic games.

\subsubsection{Materials}

This experiment consisted of three phases: a priming phase, a training phase and a final test phase.

Firstly, the priming phase was composed of eight syllogisms whose themes were related to unknown food (primary knowledge, noted "K1" in results) or made-up grammar (secondary knowledge, noted "K2" in results).

Secondly, the training phase was introduced as follows: 
Now, we suggest you do several exercises.

Each page will contain a problem. As before, you will have to judge its validity.

After confirmation of your answer, an answer key will be presented to you. It will help you improve your understanding of the problems.

The purpose of these exercises is to prepare you to take a "final test".

Take the practice time you need. You decide when to end the training phase. The goal is to obtain as many correct answers as possible in the final test!

Reminder: in the statements, the premises (first two lines) must be considered true and the conclusion must only be accepted if it follows logically from the premises.

Each page then displayed only one syllogism at a time. The content was secondary knowledge related to mathematics. For example:

All Barry volumes are calculated by $\sum(|R x-1| / 5 \pi)$,

Some volumes of disphenoid are calculated by $\sum(|R x-1| / 5 \pi)$,

So some volumes of disphenoid are Barry volumes.

Participants then answered whether or not the conclusion followed from the premises. After confirmation of their choice, an automatic feedback was displayed. This feedback (i) informed the participant if his/her answer was correct or incorrect, (ii) resumed the syllogism by explaining it, (iii) specified the rule in $\mathrm{ABC}$ form and (iv) provided the participant with the choice of continue training or taking the final test. For example:

Correct answer.

When: all Barry volumes are calculated by $\sum(|R x-1| / 5 \pi)$,

Some volumes of disphenoid are calculated by $\sum(|R x-1| / 5 \pi)$,

We cannot conclude that some volumes of disphenoid are Barry volumes.

Here is the general rule:

All As are Bs,

Some Cs are Bs,

"So some Cs are As" does not follow logically from the premises.

You choose to: 


\section{Do another exercise to train}

\section{Take the final test and try to get as many correct answers as possible}

The training phase proposed a maximum of thirty syllogisms of six different forms (the six different types of syllogisms were presented in repetitive blocks five times).

Thirdly, as the terms $\mathrm{ABC}$ were used to present the rules during the training phase, the final test phase involved the letters LWR and consisted of the six forms of syllogisms seen in the previous phases (" $A$ is $B, C$ is $B$, So $C$ is $A$ " invalid, " $A$ is $B, C$ is $A$, So $C$ is $B$ " valid, " $A$ is $B, C$ is not $B$, So $C$ is not $A$ " valid, " $A$ is $B, C$ is not $A$, So $C$ is not $B$ " invalid, " $A$ is $B, A$ is $C$, So $C$ is $B$ " valid, " $A$ is $B$, $A$ is not $C$, So $C$ is not $B$ " invalid).

\subsubsection{Procedure}

Experiment 3 was conducted online with Qualtrics. In the priming phase, after having read the same explanations concerning syllogisms as in the previous experiments, participants were confronted with two pages of four syllogisms (i.e. 8 syllogisms in total) whose content was unknown words either related to primary knowledge (food, $\mathrm{n}=112$ ) or related to secondary knowledge (grammar rules, $\mathrm{n}=115$ ). They then filled in the dependent variables used in previous experiments about these first eight

processed syllogisms in order to verify the positive influence of primary knowledge (enjoyment in answering questions, desire to find the correct answers, confidence in the given answers and perceived cognitive load). All participants were then directed to the training phase consisting of maximum 30 syllogisms with secondary knowledge content (mathematics) only and feedback for each of their answers. The relative performance in the training phase was evaluated as well as the number of exercise pages completed (left to the choice of the participant). Participants were then asked to complete the final test. They next filled in the items of the dependent variables a second time, answering the demographic questions as well as the achievement goals questionnaire as they did in the previous experiments. The time spent on each phase was measured.

\subsubsection{Data analyses}

In line with previous experiments, a priming phase using primary knowledge content would increase the number of exercises completed during the training phase. Compared to a secondary knowledge sequence, presenting primary knowledge before secondary knowledge would enhance 
LWR final test performance, participants' engagement and confidence, and would decrease their perceived cognitive load (Hypothesis 2).

The statistical analyses performed were similar to those in Experiment 2. Repeated t-tests were used to explore differences in scores on observed variables between the priming phase and the final LWR test phase. No participants reported having copied the rules given in the feedback or being familiar with the themes used. One item allowed participants to inform us that they took a break of more than 30 seconds during the experiment: 200 participants did not take a break, so we excluded the other 27 when the variable tested was speed.

\subsection{Results}

\subsubsection{Priming phase}

Even if the priming phase was rather short with only eight problems, primary knowledge positively influenced all the variables observed (except speed) (Table 3). The higher the estimated level in mathematics, the higher was the performance in the priming phase $(r=0.15, p=.02 ; F(1,217)=4.13$, $\left.p=.04, \eta^{2}=0.02\right)$. The higher the performance approach score, the greater was the wish to find the correct answers $\left(r=0.18, p=.006 ; F(1,217)=5.17, p=.02, \eta^{2}=0.02\right)$ and the higher the performance avoidance score, the less confidence participants had in their responses $(r=-0.21, p=.002$; $\left.F(1,217)=3.91, p=.05, \eta^{2}=0.02\right)$.

\subsubsection{Training phase}

Regarding the training phase, presenting primary or secondary knowledge in the priming phase did not have a significant effect on the number of problems completed $\left(F(1,218)=0.47, p=.49, \eta^{2}=0.002\right)$. Of the 30 problems proposed during the training, 3 participants completed 14. However, most participants completed $3(n=34)$ or fewer than $3(n=113)$. Only 41 participants $(18 \%)$ trained on the 6 possible syllogisms. However, the knowledge type used in the priming phase influenced relative performance in the training phase: when the priming phase used primary knowledge content, relative performance in the training phase was higher $\left(\mathrm{M}_{\mathrm{K} 1}=71.47 \pm 30.24\right.$ vs. $\left.\mathrm{M}_{\mathrm{K} 2}=56.82 \pm 35.42\right)$ $\left(F(1,217)=11.69, p<.001, \eta^{2}=0.05\right)$. Speed of problem solving $\left(\mathrm{M}_{\mathrm{K} 1}=3.53 \pm 2.68 v s . \mathrm{M}_{\mathrm{K} 2}=3.35 \pm 1.41\right)$ $\left(F(1,190)=0.35, \quad p=.55, \quad \eta_{p}^{2}=0.002\right) \quad$ or speed of feedback processing $\left(\mathrm{M}_{\mathrm{K} 1}=5.40 \pm 2.93\right.$ vs. $\left.\mathrm{M}_{\mathrm{K} 2}=5.42 \pm 3.21\right)\left(F(1,190)=0.004, p=.95, \eta^{2}<0.001\right)$ were not influenced by the knowledge type used in the priming phase. 
According to survival analyses, women $(M=3.80 \pm 3.08)$ completed more exercises than men $(M=2.46 \pm 1.68)\left(\chi^{2}(1)=10.6, p=.001\right)$ while men were less well represented in our sample. The counterbalancing of the gender representation of the samples in experiments 2 and 3 lead to the same results: women seemed more persistent. In addition, participants with a strong relative negative feedback score $(M=4.08 \pm 3.19)$ chose to complete more exercises than participants with a low negative feedback score $(M=3.03 \pm 2.53)\left(\chi^{2}(1)=7.9, p=.005\right)$ whether the priming phase used primary or secondary knowledge. Participants were therefore generally more persistent when faced with more negative feedback. No other characteristics favoring persistence in the training phase could be highlighted whether the priming phase used primary or secondary knowledge. Analyses did not account for a mediating or modulation effect of the number of exercises completed on LWR final test performance.

\subsubsection{Final test phase}

In the final LWR test phase, participants who had benefited from a primary knowledge content in the priming phase performed better, enjoyed answering the last questions more, had a higher wish to find the correct answers and had more confidence in their answers (Table 4). The higher the estimated level in mathematics, the higher was the wish to find answers to the final test $(r=0.17, p=.009$; $\left.F(1,217)=5.53, p=.02, \eta_{p}^{2}=0.02\right)$ and the lower the perceived cognitive load $(r=-0.16, p=.01$; $\left.F(1,217)=5.08, p=.02, \eta^{2}=0.02\right)$.

\subsubsection{The evolution between the priming and the final test phases}

By comparing the variables at the time of the priming phase and at the time of the final test phase, a primary knowledge priming would have stabilized the enjoyment in answering questions (difference between the initiation phase and the test phase: primary knowledge, $t(111)=-1.31, p=.19, d=0.13$; secondary knowledge, $t(114)=-5.52, p<.001, d=0.51)$ and the wish to find the correct answers (difference between the initiation phase and the test phase: primary knowledge, $t(111)=-0.85, p=.39$, $d=0.07$; secondary knowledge, $t(114)=-2.93, p=.004, d=0.25)$. Confidence in the given answers increased during the transition from the priming phase to the final LWR test for both types of knowledge but to a lesser extent for primary knowledge $(t(111)=-2.55, p=.01, d=0.18)$ compared to secondary knowledge $(t(114)=-4.82, p<.001, d=0.43)$. Similarly, the perceived cognitive load decreased to a lesser extent for primary knowledge $(t(111)=3.26, p=.001, d=0.27)$ than secondary knowledge $(t(114)=6.22, p<.001, d=0.55)$. 


\subsection{Discussion}

Experiment 3 confirmed once more the positive effect of primary knowledge. During the priming phase, performance, emotional and cognitive engagement, as well as confidence in responses were higher and the perceived cognitive load was lower (Hypothesis 1). However, contrary to expectations, the number of free exercises completed was not influenced by the knowledge type used in the priming phase. The lack of effect on the number of exercises as well as the lack of influence of personal characteristics on secondary knowledge could be due to the fact that completing the final test had indeed no stake in this study: participants performed the test only for their personal satisfaction and may have preferred the challenge of taking the final test without using training which may seem daunting. To overcome this problem, a reward should be added according to the score obtained in the final test (mimicking the effects of the extrinsic motivation often necessary for learning, Legault, 2016). The experiment should also be conducted during a course where time is constrained, fixed and reserved for learning as in the first two experiments. This may encourage participants to consider the training phase more carefully. However, the beneficial effect of primary knowledge was apparent since relative performance in the training phase was better when the priming phase used this type of knowledge. Experiment 3 showed especially that, compared to a secondary knowledge priming, a primary knowledge priming promoted the performance on the final test, the enjoyment of answering questions, the wish to find the correct answers and the confidence in the given answers (Hypothesis 2). A priming phase using primary knowledge would also maintain the enjoyment of answering questions and the wish to find the correct answers throughout the study. Finally, even in a short form (eight syllogisms presented in two steps), a priming phase using primary knowledge is favorable to the participants' performance and commitment. Introducing new course content through a small introduction with primary knowledge contents would therefore be beneficial for learning.

\section{General discussion}

We used an evolutionary approach to knowledge to determine if this is useful for understanding learners' motivation, learning and perseverance (Geary \& Berch, 2016). From this perspective, there are two broad types of knowledge: primary knowledge for which our brain would have evolved (processed effortlessly, quickly and intrinsically motivating) and secondary knowledge for which our cognitive architecture would not have had enough time to evolve (requiring cognitive resources for processing, time and effort to be learned, and for which we would have little motivation). Thus the knowledge that results in learning is secondary knowledge and is thought of as constructed from primary knowledge. We used primary knowledge to foster the involvement and performance of 
individuals in a learning task that is not inherently engaging: learning the normative rules of logic. In three experiments, we varied the contents of logical problems (related to primary or secondary knowledge) in a first phase and observed the impact on participants' involvement in the training phase and on performance in a final test. The results showed that participants performed better, were more motivated and experienced less cognitive load when faced with primary knowledge contents. Primary knowledge contents involved more participants who chose to stay longer on the training task regardless of their personal characteristics. However, only focusing on primary knowledge is not expected to be sufficient for secondary learning. Finally, this study argues in favor of a presentation of new contents to be learned that would first involve an introduction, even a short one, of primary knowledge to motivate and increase learning performance.

\section{Being "simply" efficient when faced with primary knowledge}

The first result of this study confirms the efficiency of individuals in processing primary knowledge even if it is only used as a content for secondary knowledge. Indeed, the results clearly showed that, compared to secondary knowledge contents, primary knowledge contents promoted individual performance, motivation as well as confidence and reduce perceived cognitive load (Hypothesis 1). This argues in favor of the characteristics attributed to these two knowledge types by the evolutionary approach (Geary \& Berch, 2016; Sweller, 2016). Primary knowledge, for which our brain has evolved, would be processed easily, quickly and without the need for cognitive resources, unlike secondary knowledge, which would require effort and time. This distinction is consistent with the one used in adaptive memory theory (Nairne, 2016) but now extended to more complex learning. Thus, we would be efficient for primary knowledge, even if it concerns unknown objects (Lespiau \& Tricot, 2018).

However, being efficient and remaining on primary knowledge contents is not sufficient to allow secondary learning (Hypothesis 2). Experiments 1 and 2 illustrate this fact: training with primary knowledge did not promote performance in the final test and was no different from training with secondary knowledge. Individuals would be efficient on primary knowledge contents but "would go no further" in extracting the formal logic rule. It is not enough to remain on primary knowledge to learn. Indeed, it is naïve to believe that telling children to play, explore or imitate is enough to learn secondary knowledge (Kirschner et al., 2006). Primary knowledge and its acquisition mechanisms are not sufficient for the acquisition of secondary knowledge because they are precisely primary and not adapted to this new knowledge, which is difficult to learn (Geary \& Berch, 2016). 
Using primary knowledge to introduce secondary knowledge: motivating learners regardless of their characteristics and fostering learning

While primary knowledge alone is not sufficient, it serves as the basis for learning all other knowledge (Geary \& Berch, 2016). Thanks to its characteristics, primary knowledge could encourage learners' involvement and persistence in the training phase, whatever their characteristics (Experiment 2, Hypothesis 3). Primary knowledge would have a universal positive influence, as defined by evolutionary theory. This is not the case for secondary knowledge which requires effort and time to be learned and often a particular motivation. Indeed, the study shows that involvement in problems with secondary knowledge content is facilitated by individuals' specific characteristics. In particular, those characteristics should be a strong wish to find the correct answers and a fear of missing an important element for the final test. It would therefore seem interesting to rely on primary knowledge to motivate individuals and place them all on an equal basis, particularly in the context of a learning task.

Faced with primary knowledge, individuals would be "simply" efficient and would not seek to extract a particular common rule. Thus, training composed only of primary knowledge would not be enough to learn. However, because of their characteristics, the secondary knowledge presented alone would demotivate individuals, saturate their working memory and prevent learning. To learn, one should therefore neither remain in the "comfort zone" of primary knowledge, nor begin "in the heart of the matter" with secondary knowledge alone. The idea would then be to use the characteristics of the two knowledge types in a combined way by first presenting (i) a content of the problem related to primary knowledge in order to reassure individuals in their abilities and motivate them, then (ii) challenging them with a secondary knowledge content to enable learning (Experiment 3 ). The results clearly showed that such a sequence is favorable to learners' performance, motivation and confidence during the final test (Hypothesis 2). This procedure would also maintain individual motivation levels throughout the study. Finally, this study continues research that has demonstrated that primary knowledge can facilitate secondary knowledge acquisition and learning (Paas \& Sweller, 2012; Youssef et al., 2012; Youssef-Shalala, 2014) and extends the results to motivation and persistence in the learning task.

The "primary then secondary knowledge" presentation procedure can come close to the concept of concreteness fading (Goldstone \& Son, 2005; McNeil \& Fyfe, 2012). Learning would be promoted when concrete representations are introduced first and gradually move towards more abstract and symbolic representations. However, the use of primary knowledge appears to ignore concreteness or 
familiarity since the contents used in these three experiments invoked objects unknown to the participants. Primary knowledge would therefore make it possible to develop an educational method that is relatively simple to implement and efficient for most if not all learners, whatever their characteristics.

This presentation procedure seems promising and will have to be tested on more usual learning contents than normative logic rules. Some courses lend themselves better to contents exercises than others such as ancient language courses or the teaching of statistics which do not engage the students at first sight, or even discourage them. It will then be necessary to consider how to present mathematics problems to learners without them perceiving this attempt as infantilizing. It will also be interesting to investigate further the cognitive mechanisms at play and the impact of individual differences according to the types of knowledge at stake. The three experiments presented in this paper seem to illustrate that primary knowledge has a positive influence regardless of the characteristics of the individuals completing the task. This universality of primary knowledge has yet to be argued, particularly as a starting point for content that is more difficult to learn and could be tested with different populations (e.g. individuals with learning difficulties, elderly people) and taking culture into account. Moreover, if a priming of primary knowledge could be a solution to the eternal inequality of motivation between learners, it remains to be seen how long this motivation lasts. Studies assessing the motivational impact of primary knowledge over time will be major assets in answering this question. Finally, primary knowledge can be integrated with the explanations necessary to understand and thus learn secondary knowledge. In Experiment 3, the feedback used was simple and direct, but more would probably be needed to stablish understanding. For example, primary knowledge could help students with difficulties to understand different problems through alternative representations.

This paper proposes to use the characteristics of the two types of knowledge defined by the evolutionary approach (Geary \& Berch, 2016) to motivate learners and promote learning processes. Indeed, learning secondary knowledge (e.g. rules of formal logic) is a costly process (in time and cognitive resources) and not very motivating. When logical problems focused on primary (low-cost) knowledge, performance and commitment were promoted and perceived cognitive load was lower. Moreover, presenting primary knowledge first would motivate individuals and reassure them about their abilities. Continuing with secondary knowledge would test learning skills, mobilizing rule extraction skills. This presentation of primary and secondary knowledge seems more efficient both in terms of individuals' performance and motivation. However, it would seem that presenting a new 
course directly "in the heart of the matter" (secondary knowledge) without going through a taming phase reduced performance and undermined individuals. Finally, the study argues in favor of intuitive practices by teachers who use primary knowledge contents to reassure and interest students. Who hasn't started learning to count with candy or been introduced to fractions with pieces of cake?

\section{$7 \quad$ Ethical approval}

This study was conducted in accordance with the ethical standards of the institutional and national guidelines and with the Declaration of Helsinki (2008). Informed consent was obtained from all individual participants included in the study.

\section{Conflict of Interest}

The authors declare that the research was conducted in the absence of any commercial or financial relationships that could be construed as a potential conflict of interest.

\section{References}

Allison, P. D. (2014). Event history and survival analysis: Regression for longitudinal event data. USA: SAGE publications.

Binkley, M., Erstad, O., Herman, J., Raizen, S., Ripley, M., Miller-Ricci, M., \& Rumble, M. (2012). Defining twenty-first century skills. In Griffin, P., McGaw, B., \& Care, E. (Eds.), Assessment and teaching of 21st century skills (pp. 17-66). Dordrecht: Springer.

Braver, T. S., Krug, M. K., Chiew, K. S., Kool, W., Westbrook, J. A., Clement, N. J., Adcock, R. A., Barch, D. M., Botvinick, M. M., Carver, C. S., Cools, R., Custers, R., Dickinson, A., Sweck, C. S., Fishbach, A., Gollwitzer, P. M., Hess, T. M., Isaacowitz, D. M., Mather, M., Murayama, K., Pessoa, L., Samanez-Larkin, G. R., \& Somerville, L. H. (2014). Mechanisms of motivationcognition interaction: challenges and opportunities. Cognitive, Affective, \& Behavioral Neuroscience, 14(2), 443-472. doi: 10.3758/s13415-014-0300-0

Castro-Alonso, J. C., Ayres, P., \& Paas, F. (2015). Animations showing Lego manipulative tasks: Three potential moderators of effectiveness. Computers \& Education, 85, 1-13. doi: 10.1016/j.compedu.2014.12.022

Chu, F. W., vanMarle, K., \& Geary, D. C. (2015). Early numerical foundations of young children's mathematical development. Journal of Experimental Child Psychology, 132, 205-212. doi: 10.1016/j.jecp.2015.01.006 
Cosmides, L., \& Tooby, J. (2004). Knowing thyself: The evolutionary psychology of moral reasoning and moral sentiments. The Ruffin Series of the Society for Business Ethics, 4, 93-128. doi: 10.5840/ruffinx200447

Darnon, B., \& Butera, F. (2005). Buts d'accomplissement, stratégies d'étude, et motivation intrinsèque: présentation d'un domaine de recherche et validation française de l'échelle d'Elliot et McGregor (2001). L'année psychologique, 105(1), 105-131.

Elliot, A. J., \& McGregor, H. A. (2001). A $2 \times 2$ achievement goal framework. Journal of personality and social psychology, 80(3), 501-519. doi: 10.1037/0022-3514.80.3.501

Elliot, A. J., \& Murayama, K. (2008). On the measurement of achievement goals: Critique, illustration, and application. Journal of Educational Psychology, 100(3), 613-628. doi: 10.1037/00220663.100.3.613

Ellis, G. F. (2008). Commentary on "An evolutionarily informed education science” by David C. Geary. Educational Psychologist, 43(4), 206-213. doi: 10.1080/00461520802392216

Geary, D. C. (2007). Educating the evolved mind: Conceptual foundations for an evolutionary educational psychology. In Carlson, J. S., \& Levin, J. R. (Eds.), Educating the evolved mind: Conceptual foundations for an evolutionary educational psychology (pp. 1-99). Greenwich: Information Age.

Geary, D. C. (2008). An evolutionarily informed education science. Educational Psychologist, 43(4), 179-195. doi: 10.1080/00461520802392133

Geary, D. C., \& Berch, D. (2015). Evolutionary approaches to understanding children's academic achievement. In Scott, R. A., \& Kosslyn, S. M. (Eds.), Emerging Trends in the Social and Behavioral Sciences (pp.1-10). Hoboken: Wiley. doi: 10.1002/9781118900772.etrds0123

Geary, D. C., \& Berch, D. (2016). Evolution and Children's Cognitive and Academic Development. In Geary, D. C., \& Berch, D. (Eds.), Evolution and Children's Cognitive and Academic Development (pp.217-249). Switzerland: Springer International Publishing. doi: 10.1007/978-3319-29986-0_9

Geary, D. C., \& Bjorklund, D. F. (2000). Evolutionary developmental psychology. Child development, 71(1), 57-65. doi: 10.1111/1467-8624.00118

Gelin, M., Bonin, P., Méot, A., \& Bugaiska, A. (2018). Do animacy effects persist in memory for context?. The Quarterly Journal of Experimental Psychology, 71(4), 965-974. doi : 10.1080/17470218.2017.1307866

Glenberg, A. M., Goldberg, A. B., \& Zhu, X. (2011). Improving early reading comprehension using embodied CAI. Instructional Science, 39(1), 27-39. doi: 10.1007/s11251-009-9096-7 
Goldstone, R. L., \& Son, J. Y. (2005). The transfer of scientific principles using concrete and idealized simulations. The Journal of the Learning Sciences, 14(1), 69-110. doi: 10.1207/s15327809j1s1401_4

Hattie, J., \& Timperley, H. (2007). The power of feedback. Review of educational research, 77(1), 81112. doi: $10.3102 / 003465430298487$

Huff, S. M., Stripling, C. T., Boyer, C., \& Stephens, C. A. (2016). Investigating Factors that Influence Achievement Goal Orientation and Educational Practices in Undergraduate Agricultural Sciences and Natural Resource Students. NACTA Journal, 60(4), 423-431.

Hummel, J. E., \& Holyoak, K. J. (2005). Relational reasoning in a neurally plausible cognitive architecture an overview of the lisa project. Current Directions in Psychological Science, 14(3), 153-157. doi: 10.1111/j.0963-7214.2005.00350.x

Kaminski, J. A., Sloutsky, V. M., \& Heckler, A. F. (2006). Do children need concrete instantiations to learn an abstract concept? In Sun, R., \& Miyake, N. (Eds), Proceedings of the 27th Annual Conference of the Cognitive Science Society (pp. 411-416). Mahwah, NJ: Lawrence Erlbaum.

Kim, C., Park, S. W., \& Cozart, J. (2014). Affective and motivational factors of learning in online mathematics courses. British Journal of Educational Technology, 45(1), 171-185. doi: 10.1111/j.1467-8535.2012.01382.x

Kirschner, F., Paas, F., \& Kirschner, P. A. (2011). Task complexity as a driver for collaborative learning efficiency: The collective working-memory effect. Applied Cognitive Psychology, 25(4), 615-624. doi: 10.1002/acp.1730

Kirschner, F., Paas, F., Kirschner, P. A., \& Janssen, J. (2011). Differential effects of problem-solving demands on individual and collaborative learning outcomes. Learning and Instruction, 21(4), 587599. doi: 10.1016/j.learninstruc.2011.01.001

Kirschner, P. A., Sweller, J., \& Clark, R. E. (2006). Why minimal guidance during instruction does not work: An analysis of the failure of constructivist, discovery, problem-based, experiential, and inquiry-based teaching. Educational psychologist, 41(2), 75-86. doi: 10.1207/s15326985ep4102_1

Leding, J. K. (2018). The animacy advantage in memory: Manipulations of levels of processing and survival processing. American Journal of Psychology, 131(3), 273-281. doi: 10.5406/amerjpsyc.131.3.0273

Legault, L. (2016). Intrinsic and Extrinsic Motivation. Encyclopedia of Personality and Individual Differences, 1-4. doi: 10.1007/978-3-319-28099-8_1139-1

Lespiau, F., \& Tricot, A. (2018). Primary knowledge enhances performance and motivation in reasoning. Learning and Instruction, 56, 10-19. doi.org/10.1016/j.learninstruc.2018.02.007 
Markovits, H., \& Lortie-Forgues, H. (2011). Conditional reasoning with false premises facilitates the transition between familiar and abstract reasoning. Child Development, 82(2), 646-660. doi: $10.1111 / \mathrm{j} .1467-8624.2010 .01526 . x$

Mavilidi, M. F., Okely, A. D., Chandler, P., Cliff, D. P., \& Paas, F. (2015). Effects of integrated physical exercises and gestures on preschool children's foreign language vocabulary learning. Educational Psychology Review, 27(3), 413-426. doi: 10.1007/s10648-015-9337-z

McNeil, N. M., \& Fyfe, E. R. (2012). "Concreteness fading” promotes transfer of mathematical knowledge. Learning and Instruction, 22(6), 440-448. doi: 10.1016/j.learninstruc.2012.05.001

Morsanyi, K., Devine, A., Nobes, A., \& Szücs, D. (2013). The link between logic, mathematics and imagination: Evidence from children with developmental dyscalculia and mathematically gifted children. Developmental science, 16(4), 542-553. doi: 10.1111/desc.12048

Nairne, J. S. (2016). Adaptive memory: Fitness-relevant "tunings" help drive learning and remembering. In C. D. Geary \& B. D. Berch (Eds.), Evolutionary perspectives on child development and education (pp. 251-269). Cham, Switzerland: Springer International.

Nairne, J. S., Pandeirada, J. N. S., \& Thompson, S. R. (2008). Adaptive memory: The comparative value of survival processing. Psychological Science, 19, 176-180. doi:10.1111/j.14679280.2008.02064.x

Nokes-Malach, T. J., Richey, J. E., \& Gadgil, S. (2015). When is it better to learn together? Insights from research on collaborative learning. Educational Psychology Review, 27(4), 645-656. doi: $10.1007 / \mathrm{s} 10648-015-9312-8$

Paas, F., \& Ayres, P. (2014). Cognitive load theory: A broader view on the role of memory in learning and education. Educational Psychology Review, 26(2), 191-195. doi: 10.1007/s10648-014-9263-5

Paas, F., Renkl, A., \& Sweller, J. (2003). Cognitive load theory and instructional design: Recent developments. Educational psychologist, 38(1), 1-4. doi: 10.1207/S15326985EP3801_1

Paas, F., \& Sweller, J. (2012). An evolutionary upgrade of cognitive load theory: Using the human motor system and collaboration to support the learning of complex cognitive tasks. Educational Psychology Review, 24(1), 27-45. doi: 10.1007/s10648-011-9179-2

Ping, R., \& Goldin-Meadow, S. (2010). Gesturing saves cognitive resources when talking about nonpresent objects. Cognitive Science, 34(4), 602-619. doi: 10.1111/j.1551-6709.2010.01102.x

Richerson, P. J., \& Boyd, R. (2005). Not by genes alone: How culture transformed human evolution. Chicago: University of Chicago Press. 
Roszkowski, M. J., \& Soven, M. (2010). Did you learn something useful today? An analysis of how perceived utility relates to perceived learning and their predictiveness of satisfaction with training. Performance Improvement Quarterly, 23(2), 71-91. doi: 10.1002/piq.20082

Roussel, S., Joulia, D., Tricot, A., \& Sweller, J. (2017). Learning subject content through a foreign language should not ignore human cognitive architecture: A cognitive load theory approach. Learning and Instruction, 52, 69-79. doi: 10.1016/j.learninstruc.2017.04.007

Ryan, R., \& Deci, E. (2000). Intrinsic and extrinsic motivations: Classic definitions and new directions. Contemporary Educational Psychology, 25(1), 54-67.

Stanovich, K. E., \& West, R. F. (2000). Individual differences in reasoning: Implications for the rationality debate? Behavioral and brain sciences, 23(05), 701-717.

Sweller, J. (2008). Instructional implications of David C. Geary's evolutionary educational psychology. Educational Psychologist, 43(4), 214-216. doi: 10.1080/00461520802392208

Sweller, J. (2015). In academe, what is learned, and how is it learned?. Current Directions in Psychological Science, 24(3), 190-194. doi: 10.1177/0963721415569570

Sweller, J. (2016). Cognitive Load Theory, Evolutionary Educational Psychology, and Instructional Design. In Geary, D. C., \& Berch, D. (Eds.), Evolution and Children's Cognitive and Academic Development (pp.291-306). Switzerland: Springer International Publishing. doi: 10.1007/978-3319-29986-0_9

Sweller, J., Ayres, P., \& Kalyuga, S. (2011). Cognitive load theory. New York: Springer.

Sweller, J., \& Sweller, S. (2006). Natural information processing systems. Evolutionary Psychology, 4(1), 434-458. doi: 10.1177/147470490600400135

Toumpaniari, K., Loyens, S., Mavilidi, M. F., \& Paas, F. (2015). Preschool children's foreign language vocabulary learning by embodying words through physical activity and gesturing. Educational Psychology Review, 27(3), 445-456. doi: 10.1007/s10648-015-9316-4

Tricot, A. (2018). Scientific reasoning as domain specific knowledge. In F. Fisher, C. Chinn, K. Engelmann \& J. Osborne (Eds.), Scientific reasoning and argumentation: The roles of domainspecific and domain-general knowledge (pp. 271-277). New York: Routledge.

Van Gog, T., Paas, F., Marcus, N., Ayres, P., \& Sweller, J. (2009). The mirror neuron system and observational learning: Implications for the effectiveness of dynamic visualizations. Educational Psychology Review, 21(1), 21-30. doi: 10.1007/s10648-008-9094-3

Youssef, A., Ayres, P., \& Sweller, J. (2012). Using general problem-solving strategies to generate ideas in order to solve geography problems. Applied Cognitive Psychology, 26(6), 872-877. doi: 10.1002/acp. 2888 
Youssef-Shalala, A., Ayres, P., Schubert, C., \& Sweller, J. (2014). Using a general problem-solving strategy to promote transfer. Journal of Experimental Psychology: Applied, 20(3), 215-231. doi: 10.1037/xap0000021 


\section{Tables}

Table 1 : Results from ANCOVAs regarding the influence of the two knowledge types on the dependent variables in Experiment 1. Analyses are described with means (M) and standard deviation (SD).

\begin{tabular}{llllllll}
\hline & \multicolumn{2}{l}{ Primary Knowledge } & \multicolumn{2}{l}{ Secondary Knowledge } & F (1,96) & $p$ & $\eta^{2} p$ \\
& $\mathrm{M}$ & $\mathrm{SD}$ & $\mathrm{M}$ & $\mathrm{SD}$ & & & \\
\hline Performance (training) & 77.75 & 16.65 & 61.14 & 16.09 & 27.58 & $<.001$ & 0.22 \\
Performance final test (ABC) & 48.58 & 17.81 & 49.52 & 13.44 & 0.09 & .76 & $<0.001$ \\
Enjoyment answering questions & 51.58 & 29.02 & 36.36 & 26.14 & 7.50 & .007 & 0.07 \\
Wish to find the correct answers & 71.58 & 25.86 & 60.42 & 29.35 & 4.33 & .04 & 0.04 \\
Confidence & 48.96 & 31.26 & 36.98 & 29.35 & 4.06 & .04 & 0.04 \\
Perceived cognitive load & 50.84 & 22.55 & 63.89 & 21.02 & 9.42 & .003 & 0.09 \\
\hline
\end{tabular}

Table 2 : Results from ANCOVAs regarding the influence of the two knowledge types on the dependent variables in Experiment 2. Analyses are described with means (M) and standard deviation (SD).

\begin{tabular}{|c|c|c|c|c|c|c|c|}
\hline & \multicolumn{2}{|c|}{ Primary Knowledge } & \multicolumn{2}{|c|}{ Secondary Knowledge } & \multirow[t]{2}{*}{$F(1,91)$} & \multirow[t]{2}{*}{$p$} & \multirow[t]{2}{*}{$\eta_{p}^{2}$} \\
\hline & M & SD & M & SD & & & \\
\hline Number of exercise pages & 3.60 & 1.59 & 2.94 & 1.72 & 4.88 & .02 & 0.05 \\
\hline Relative performance (training) & 79.17 & 16.16 & 64.24 & 17.50 & 19.66 & $<.001$ & 0.18 \\
\hline Performance final test (ABC) & 52.88 & 13.58 & 48.58 & 8.99 & 3.40 & .06 & 0.04 \\
\hline Enjoyment answering questions & 50.26 & 26.39 & 44.49 & 29.67 & 1.14 & .29 & 0.01 \\
\hline Wish to find the correct answers & 65.81 & 24.39 & 73.21 & 24.04 & 2.75 & .10 & 0.03 \\
\hline Confidence & 56.31 & 27.97 & 48.24 & 30.81 & 1.97 & .16 & 0.02 \\
\hline Perceived cognitive load & 56.92 & 23.27 & 53.78 & 22.48 & 0.56 & .45 & 0.006 \\
\hline
\end{tabular}

Table 3 : Results from ANCOVAs regarding the influence of the two knowledge types on the dependent variables in the priming phase of Experiment 3. Analyses are described with means (M) and standard deviation (SD).

\begin{tabular}{llllllll}
\hline & \multicolumn{2}{l}{ Primary Knowledge } & \multicolumn{2}{l}{ Secondary Knowledge } & \multirow{2}{*}{$F(1,217)$} & $p$ & $\eta^{2} p$ \\
& $\mathrm{M}$ & $\mathrm{SD}$ & $\mathrm{M}$ & $\mathrm{SD}$ & & & \\
\hline Performance (priming phase) & 69.87 & 20.10 & 62.72 & 25.38 & 5.66 & .02 & 0.02 \\
Enjoyment answering questions & 53.12 & 29.73 & 33.32 & 28.28 & 26.45 & $<.001$ & 0.11 \\
Wish to find the correct answers & 73.24 & 23.45 & 61.16 & 29.50 & 11.85 & $<.001$ & 0.05 \\
Confidence & 46.31 & 28.30 & 31.21 & 26.46 & 18.93 & $<.001$ & 0.08 \\
Perceived cognitive load & 65.82 & 19.19 & 73.44 & 17.15 & 10.89 & .001 & 0.05 \\
Speed (pb/min) (n=200) & 2.65 & 2.08 & 2.68 & 1.50 & 0.008 & .93 & $<0.001$ \\
\hline
\end{tabular}


Table 4 : Results from ANCOVAs regarding the influence of the two knowledge types on the dependent variables in the final test phase of Experiment 3. Analyses are described with means (M) and standard deviation (SD).

\begin{tabular}{llllllll}
\hline & \multicolumn{2}{l}{ Primary Knowledge } & \multicolumn{2}{l}{ Secondary Knowledge } & F(1,217) & $p$ & $\eta_{p}^{2}$ \\
& $\mathrm{M}$ & $\mathrm{SD}$ & $\mathrm{M}$ & $\mathrm{SD}$ & & & \\
\hline Performance (final test LWR phase) & 68.60 & 19.73 & 59.13 & 20.97 & 12.60 & $<.001$ & 0.05 \\
Enjoyment answering questions & 56.78 & 47.76 & 27.28 & 28.55 & 5.86 & .02 & 0.03 \\
Wish to find the correct answers & 74.81 & 20.88 & 68.37 & 27.48 & 4.10 & .04 & 0.02 \\
Confidence & 51.41 & 27.65 & 42.80 & 27.07 & 5.73 & .02 & 0.03 \\
Perceived cognitive load & 60.38 & 20.85 & 63.86 & 17.71 & 1.96 & .16 & 0.01 \\
Speed (pb/min) (n=200) & 3.51 & 3.49 & 4.23 & 5.75 & 1.16 & .28 & 0.006 \\
\hline
\end{tabular}


11 Figures 


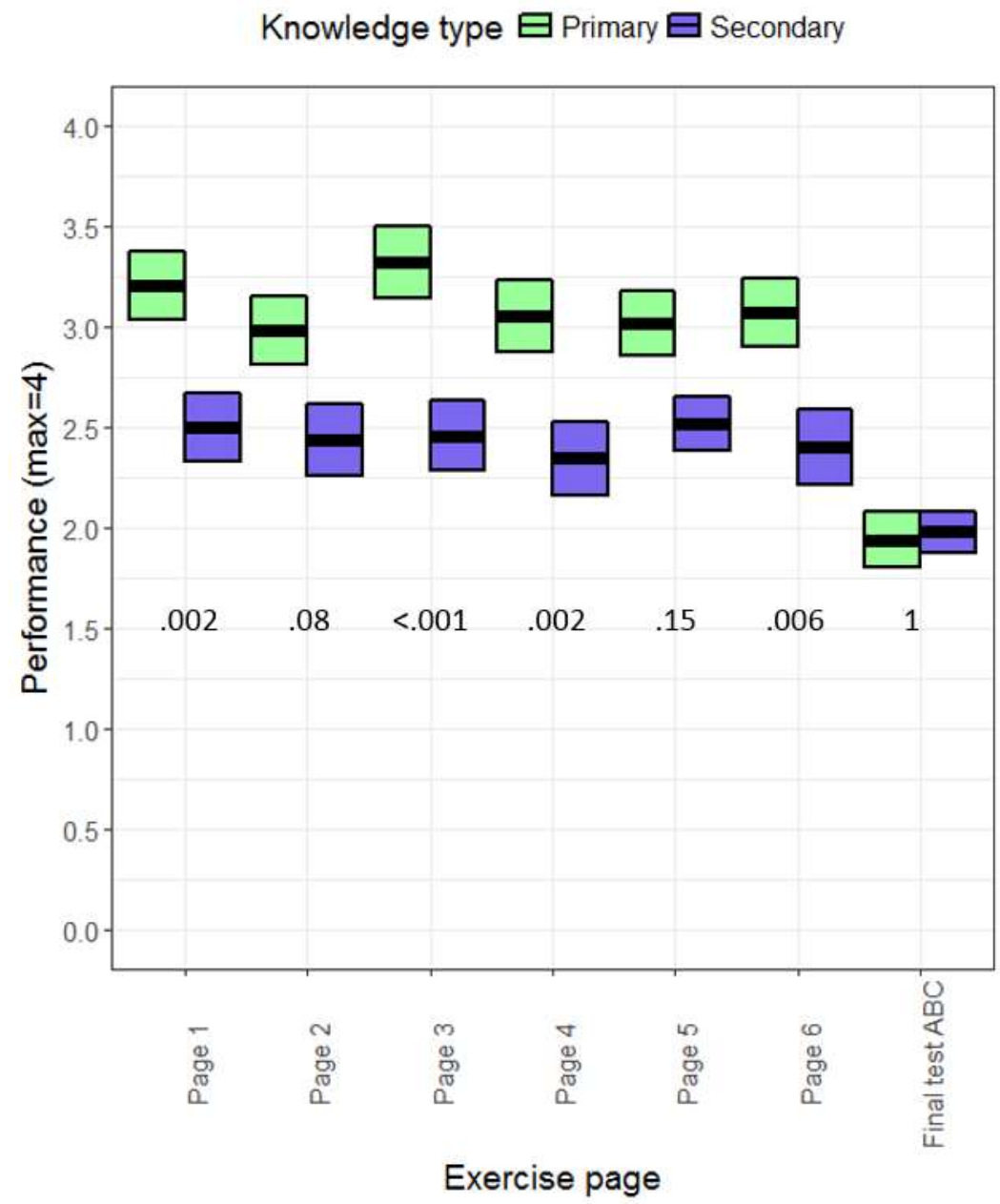

Figure 1 : Influence of the knowledge type according to the exercise pages. The displayed values are Tukey's adjusted test $p$ 's corresponding to the difference between primary and secondary knowledge contents for each page separately. Boxplots represent the mean and $95 \%$ of the confidence interval. 


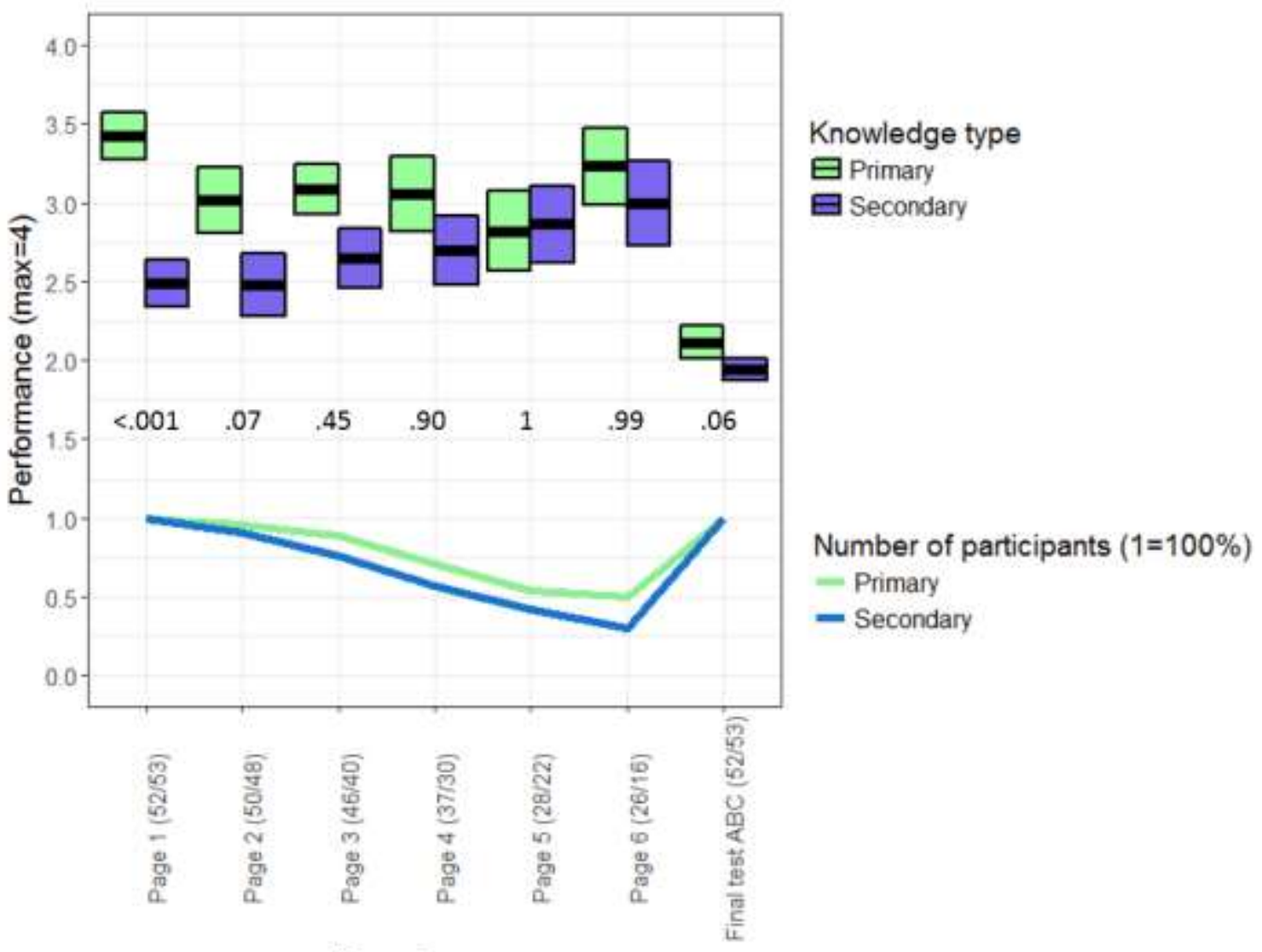

Exercise page

Figure $2:$ Influence of the knowledge type according to the exercise pages. The displayed values are Tukey's adjusted test $p$ 's. Boxplots represent the mean and $95 \%$ of the confidence interval. The lines represent the number of participants in percentages $(1=100 \%)$ according 
to the knowledge types and to the exercise page; the $\mathrm{n}$ with respect to primary and secondary knowledge are noted in the labels of the $\mathrm{x}$ axis.
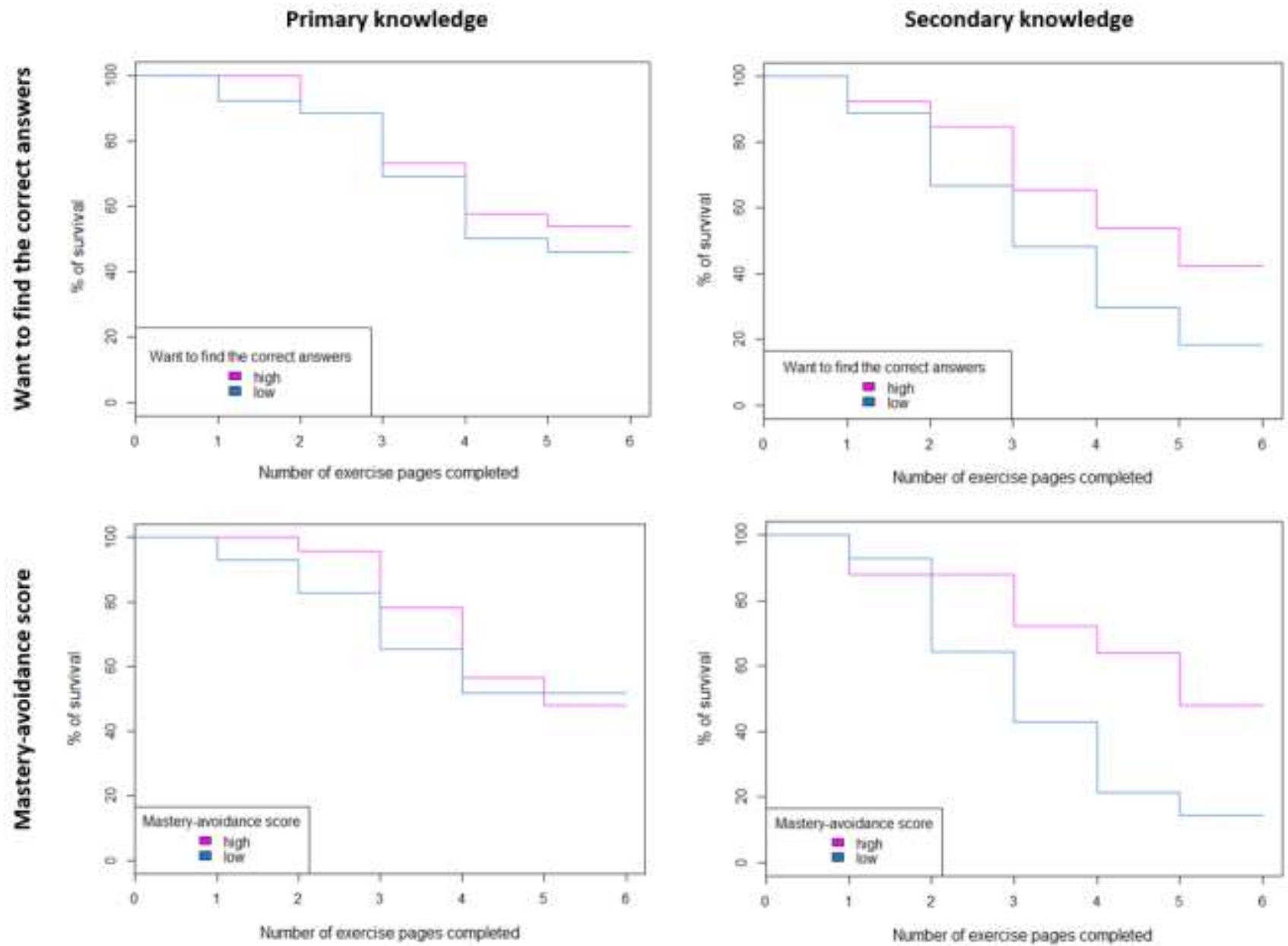

Figures 3 : Influence of the wish to find the correct answers (first line) and the mastery avoidance score (second line) in the survival/persistence of the participants during the training phase according to the knowledge type used. 